\title{
Macrostachyols A-D, oligostilbenes from Gnetum macrostachyum inhibited in vitro human platelet aggregation
}

\author{
Serm Surapinit $^{1^{*}}$, Nuttakorn Baisaeng $^{2^{(}}$ \\ ${ }^{1}$ Unit of Excellence in Integrative Molecular Biomedicine, School of Allied Health Sciences, University of Phayao, Phayao 56000, Thailand \\ ${ }^{2}$ Department of Pharmaceutical Technology, School of Pharmaceutical Sciences, University of Phayao, Phayao 56000, Thailand
}

\section{A R T I C L E I N F O}

Article Type:

Original Article

Article History:

Received: 9 February 2021

Accepted: 28 March 2021

\section{Keywords:}

Gnetum

Stilbenes

Platelet aggregation inhibitors

Oligostilbenes

Cyclooxygenase inhibitors

\begin{abstract}
A B S T R A C T
Introduction: Gnetum macrostachyum is a known Thai medicinal plant as a source of bioactive oligostilbenes, which possess platelet inhibitory activities. The study aimed to evaluate the in vitro human platelet aggregation inhibitory activities of macrostachyols A-D (compounds 1-4) isolated from the roots of G. macrostachyum. Methods: The in vitro human platelet aggregation assay was assayed with a 96-well microtiter plate format. The well-known aggregating agents were used to investigate the possible mechanism of inhibition, including adenosine diphosphate (ADP), arachidonic acid (AA), thromboxane A2 analog (U-46619), collagen, thrombin, and thrombin receptor-activating peptide-6 (TRAP-6).

Results: Compound $\mathbf{1}$ was more potent than ibuprofen (positive control) on the adenosine diphosphate- induced platelet aggregation assay $(P<0.05)$. Compound 3 was more potent than $\mathbf{1}, \mathbf{2}$, and $\mathbf{4}(P<0.05)$, but all active oligostilbenes were less potent than the positive control $(P<0.05)$ on the arachidonic acid-induced platelet aggregation assay. The oligostilbenes $1,2,3$, and 4 also displayed the inhibitory effects on the U-46619-induced platelet aggregation. The tetrameric stilbenes 1 was the only compound that exhibited inhibitory effects on thrombin-induced platelet aggregation without TRAP-6 mediated platelet aggregation.

Conclusion: The findings revealed the inhibitory effects of oligostilbenes on human platelet aggregation through a target-specific experimental design. It suggests that oligostilbenes from this plant might be applied as antiplatelet aggregation agents in platelet hyperreactivity- related diseases.
\end{abstract}

Implication for health policy/practice/research/medical education:

The present study revealed the anti-platelet aggregation inhibitory activities of oligostilbenes isolated from the roots of $G$. macrostachyum, which may suggest their applicability as anti-platelet agents for therapeutic purposes.

Please cite this paper as: Surapinit1 S and Baisaeng N. Macrostachyols A-D, oligostilbenes from Gnetum macrostachyum inhibited in vitro human platelet aggregation. J Herbmed Pharmacol. 2021;10(3):339-343. doi: 10.34172/jhp.2021.39.

\section{Introduction}

Platelets play a primarily regulatory function in hemostasis and thrombosis. Under physiological conditions, platelets play an important role in the hemostatic process in response to vascular damage. Platelets undergo three crucial steps of physiological and biochemical changes composing of initiation, activation, and perturbation. The presence of unveiled extracellular matrix protein, platelets consequently become activated by the plateletcollagen adhesion through the GPVI and integrin $\alpha 2 \beta 1$
(1). Additional pathways of platelet activation, which contribute to platelet activation, require specific stimuli such as adenosine diphosphate (ADP), thromboxane A2 (TxA2), and thrombin. Multiple-step platelet activation and biochemical changes eventually lead to thrombus formation (2). Activated platelets stimulate thrombogenesis in response to the unveil sub-endothelial matrix at the erosion site. Atherothrombosis is the phenomenon of atherosclerotic lesion disruption together with coagulation stimulation that is the major cause of death from acute

*Corresponding author: Serm Surapinit, serm.su@up.ac.th 
coronary artery and cardiovascular disorders (3). Thus, platelet function attenuation is important to prevent the progression of platelet-associated cardiovascular diseases. Anti-platelet medications, for example, aspirin, clopidogrel, dipyridamole, and ticlopidine, play important roles in thrombosis treatment and prevention. Although anti-platelet therapy is essential for the therapeutic purpose of thrombosis-related disorders, anti-platelet drugs also antagonize normal platelet function to increase the risk of serious hemorrhage (4). The discovery of newer anti-platelet agents from both edible and medicinal plants with minimal adverse effects poses a challenge. Several classes of natural products display anti-platelet activities such as curcumin, alkaloids, and lignans $(5,6)$.

The woody climber plant Gnetum macrostachyum Hook.f. is categorized into the Gnetaceae family. This plant is widely distributed in the Mekong subregion and southern Thailand, which is used as a traditional medicine to treat inflammation and pain relief. The major chemical constituents are flavonoids and stilbenoids $(7,8)$. We previously reported the in vitro inhibitory activities on human platelet aggregation by standard platelet aggregometry and static platelet adhesion assay of certain known stilbenoids from G. macrostachyum, namely transresveratrol, isorhapotigenin, gnetol, bisisorhapontigenin $B$, gnetin $C$, parvifolol A, latifolol, and gnetuhainin C (9). We also suggested that the complexity in stilbenoid structure could enhance the platelet aggregation and adhesion inhibitory activities. Moreover, one tetrameric stilbene (macrostachyols A), one trimeric stilbene (macrostachyols B), and two dimeric stilbenes (macrostachyols C-D), have been previously reported from G. macrostachyum with cytotoxicity effects (10). These four complex oligostilbenes have not been investigated for the platelet aggregation inhibitory activity by the referent protocol, due to limit amount of the compounds. The platelet aggregometry is a gold standard platelet function assay that is widely applied for the evaluation of an anti-platelet aggregation activity of the natural products (11). However, this method requires a large amount of both platelet-rich plasma and test compounds. The 96-well plate-based platelet aggregation assay is a high-throughput, reproducible, accurate, and acceptable assay for both clinical diagnosis and biological investigation of antiplatelet activity (12). Therefore, these four new oligostilbenes were obtained to evaluate the inhibitory effects on in vitro human platelet aggregation by microtiter plate assay format.

\section{Materials and Methods}

Test compounds

Plant specimens were collected from Nakhon Phanom province, Thailand in September 2006 and deposited in the herbarium of the Royal Forest Department, Bangkok, Thailand (voucher specimen number BKF 108547). The roots of this plant were collected, air-dried, and ground before extract. The ground roots $(2.5 \mathrm{~kg})$ were sequentially extracted with dichloromethane and acetone by Soxhlet extractor. The acetone extract was obtained to isolate and purify by various techniques in chromatographic methods to yield the pure form of macrostachyols A-D (1-4). The structures of the isolated oligostilbenes were elucidated by various spectroscopic techniques (10). The structures of oligostilbenes are shown in Figure 1.

Platelet-rich plasma and washed platelet preparation The healthy young volunteers were recruited base on the criteria that they were not smokers and had not taken any medications within the last two weeks, including aspirin. The volunteers were fasted overnight before blood collection by venipuncture. The human platelet-rich plasma (PRP) was prepared according to the previously described protocols (13). The $3.8 \%$ citrated blood was centrifuged at $110 \mathrm{~g}, 22 \pm 0.5^{\circ} \mathrm{C}$ for 5 minutes to separate PRP. The remaining citrated blood was further centrifuged at $3500 \mathrm{~g}$, for 5 minutes to obtain platelet-poor plasma (PPP). PRP was washed twice with calcium-free Tyrode buffer ( $\mathrm{pH} 7.35$ ), then centrifuged at $2700 \mathrm{~g}, 22 \pm 0.5^{\circ} \mathrm{C}$ for 5 minutes. Platelets were resuspended in Tyrode buffer $\mathrm{pH}$ 7.35 and kept at $37^{\circ} \mathrm{C}$.

\section{Antiplatelet aggregation assay}

Platelet aggregation assay was performed in a 96-well plate format. The $190 \mu \mathrm{L}$ of PRP was mixed with $2 \mu \mathrm{L}$ of $10 \mathrm{mM}$ $\mathrm{CaCl} 2$ solution, and $4 \mu \mathrm{L}$ of test or referent compounds for 2 minutes at $37^{\circ} \mathrm{C}$ under $1000 \mathrm{rpm}$ of orbital agitation. An aliquot of $4 \mu \mathrm{L}$ of ADP, AA, TRAP-6, and collagen were transferred to each well to initiate platelet aggregation (final concentrations of $0.5 \mathrm{mM}, 1 \mathrm{mM}, 1.5 \mathrm{mM}$, and $100 \mu \mathrm{g} / \mathrm{mL})$. After incubation ended $(18,10,10$ minutes for ADP, AA, and TRAP-6 for collagen), the absorbance of the suspension was measured on a microplate reader

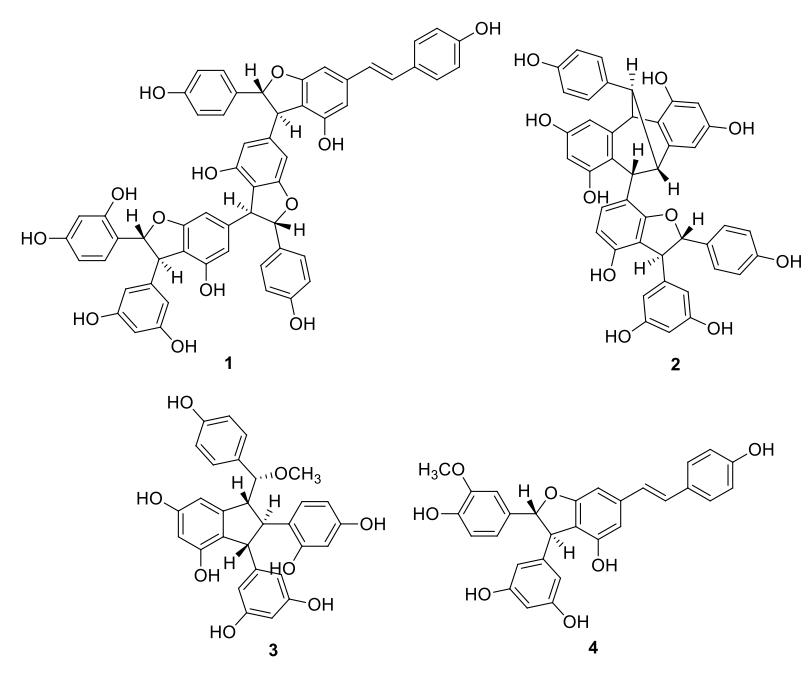

Figure 1. The structures of macrostachyols A-D (1-4) from $G$. macrostachyum. 
at $595 \mathrm{~nm}$ against PPP. The thrombin-induced platelet aggregation was assayed with washed platelet. The aliquot of $190 \mu \mathrm{L}$ washed platelet was mixed with $2 \mu \mathrm{L}$ of test or referent compound in the same manner to previous assay. To initiate platelet aggregation, an aliquot of $4 \mu \mathrm{L}$ of $50 \mathrm{IU} /$ $\mathrm{mL}$ thrombin $(0.4 \mathrm{IU} / \mathrm{mL}$ final concentration) was placed into the well, and incubated for 10 minutes. The platelet aggregates in each well were measured at $595 \mathrm{~nm}$ against PRP or suspension buffer. The inhibition percentage was calculated according to the following equation;

$I P=100 \times\left[\frac{A_{\text {blank }}-A_{\text {test }}}{A_{\text {blank }}}\right]$

Tyrode buffer solution was used as blank instead of test or referent compounds and noted as $0 \%$ aggregation. The $\mathrm{IC}_{50}$ value was calculated by the plot between the concentrations of test or referent compounds against inhibition percentage. The screening concentration of test or referent compounds was assayed at the concentration of $500 \mu \mathrm{M}$. The active compounds were selected to evaluate independently with platelets from five healthy volunteers $(n=5)$ and each experiment was duplicate.

\section{Statistical analysis}

Data analysis was performed on the IBM SPSS statistics software version 22, licensed to the University of Phayao. The $\mathrm{IC}_{50}$ values were presented as mean \pm SEM. The significant ANOVA from overall differences was analyzed by Duncan multiple comparisons. The inhibitory activities of the test compounds were grouped and categorized by Duncan's test. The statistically significant was set at a $P$ value of less than 0.05 .

\section{Results}

Compounds 1-4 were evaluated for the in vitro inhibitory effects on human platelet aggregation via 96-well plate assay format. The maximum concentration of the compounds for the screening assay was $500 \mu \mathrm{M}$. The screening results and the $\mathrm{IC}_{50}$ values were summarized in Table 1 . As the results of purinergic receptor mediated platelet aggregation assay, compound $2\left(\mathrm{IC}_{50} 62.1 \pm 3.8 \mu \mathrm{M}\right)$ was more potent than ibuprofen $\left(\mathrm{IC}_{50} 168.1 \pm 3.9 \mu \mathrm{M}\right)$, the positive control $(P<0.05)$. Compounds $\mathbf{1}, \mathbf{2}$, and 4 were inactive in the
ADP-induced platelet aggregation assay. The inhibitory effects in the cyclooxygenase-1 pathway were assessed by the arachidonic acid induced platelet aggregation. The dimeric stilbenes 3 ( $\left.\mathrm{IC}_{50} 32.5 \pm 14.2 \mu \mathrm{M}\right)$ was more potent than the compound $4\left(\mathrm{IC}_{50} 74.1 \pm 7.3 \mu \mathrm{M}\right)(P<0.05)$. The findings also demonstrated that the trimeric stilbenes $\mathbf{2}$ $\left(\mathrm{IC}_{50} 110.3 \pm 11.6 \mu \mathrm{M}\right)$ was more potent than the tetrameric stilbene $1\left(\mathrm{IC}_{50} 226.8 \pm 16.8 \mu \mathrm{M}\right)(P<0.05)$. However, those of active compounds were less potent than ibuprofen $\left(\mathrm{IC}_{50}\right.$ $4.7 \pm 0.5 \mu \mathrm{M})$, the non-selective COX inhibitor $(P<0.05)$. Compounds 1-4 were further obtained to evaluated with the U-46619, the stable synthetic TxA2 analog, induced platelet aggregation. The dimeric stilbenes $3\left(\mathrm{IC}_{50}\right.$ $32.5 \pm 14.2 \mu \mathrm{M})$ was more potent than $4\left(\mathrm{IC}_{50} 74.1 \pm 7.3 \mu \mathrm{M}\right)$, significantly $(P<0.05)$. It was also found that the trimeric stilbene $1\left(\mathrm{IC}_{50} 180.9 \pm 27.2 \mu \mathrm{M}\right)$ was more active than the trimeric stilbene $2\left(\mathrm{IC}_{50} 180.9 \pm 27.2 \mu \mathrm{M}\right)(P<0.05)$ on the $\mathrm{U}$-46619-induced platelet aggregation. The same as the results of thrombin-induced platelet aggregation assay, tetrameric stilbenes $1\left(\mathrm{IC}_{50} 24.6 \pm 5.3 \mu \mathrm{M}\right)$ was the only active compound. This active compound $\mathbf{1}$ was tested with TRAP-6 induced platelet aggregation. It was found that compound 1 was failed to inhibit TRAP-6 induced platelet aggregation. The findings also showed that compounds 1-4 were inactive in the collagen-induced human platelet aggregation assay.

\section{Discussion \\ Several antiplatelet drugs have been utilized to prevent platelet hyperfunction-associated diseases, including thrombosis and atherosclerosis. However, many anti- platelet drugs (aspirin, clopidogrel, abciximab, and terutroban) have been reported to have serious adverse events on coagulopathy, such as prolonged bleeding time, increased risks of gastrointestinal or cerebral bleeding, and palpitation (14). Therefore, it is important to develop much safer anti-platelet agents with fewer side effects. In the previous report on the inhibitory activities of several stilbenoids from G. macrostachyum, the standard Born's aggregometry was used to investigate the anti-platelet activities (9). However, certain oligostilbenes were not tested due to insufficient amounts of the test compounds. In the present study, we evaluated the potential of the}

Table 1. Human platelet aggregation inhibitory activities of the macrostachyols A-D (Compounds 1-4)

\begin{tabular}{|c|c|c|c|c|c|c|}
\hline \multirow{2}{*}{ Compounds } & \multicolumn{6}{|c|}{ Half inhibition $\left(\mathrm{IC}_{50} ; \mu \mathrm{M}\right.$; mean $\left.\pm \mathrm{SEM}\right)$} \\
\hline & ADP & AA & U-46619 & Thrombin & TRAP-6 & Collagen \\
\hline 1 & $>500$ & $226.8 \pm 16.8^{d *}$ & $180.9 \pm 27.2^{\mathrm{a}}$ & $24.6 \pm 5.3$ & $>500$ & $>500$ \\
\hline 2 & $62.1 \pm 3.8^{\mathrm{a} *}$ & $110.3 \pm 11.6^{c *}$ & $335.6 \pm 11.1^{b}$ & $>500$ & ND & $>500$ \\
\hline 3 & $>500$ & $32.5 \pm 14.2^{\mathrm{b} *}$ & $156.6 \pm 17.8^{\mathrm{a}}$ & $>500$ & ND & $>500$ \\
\hline 4 & $>500$ & $74.1 \pm 7.3^{\mathrm{c} *}$ & $281.4 \pm 15.8^{b}$ & $>500$ & ND & $>500$ \\
\hline Ibuprofen & $168.1 \pm 3.9^{b}$ & $4.7 \pm 0.5^{a}$ & $>500$ & $>500$ & ND & $96.5 \pm 8.1$ \\
\hline
\end{tabular}

ND, Not determine; ADP, Adenosine diphosphate; AA, Arachidonic acid.

$* P<0.05$ compared to the positive control, ibuprofen.

a,b,c,d Statistical grouping of the IC $\mathrm{C}_{50}$ in each treatment by Duncan's test. 
oligostilbenes on the agonist-mediated human platelet aggregation inhibition by the 96-well plate format.

We investigated the inhibitory activities of oligostilbenes on the purinergic receptor-mediated human platelet aggregation. Compound $\mathbf{2}$ was the only active oligostilbene in ADP-induced platelet aggregation assay. We previously reported that gnetuhainin $\mathrm{C}$ was inactive in the ADP-induced human platelet aggregation at the concentration of $500 \mu \mathrm{M}(9)$. Although compound $\mathbf{2}$ is naturally synthesized from the gnetuhainin $\mathrm{C}$, the trimeric stilbenes 2 was more potent than the precursor one. It indicated that increasing stilbene subunit enhanced the platelet aggregation inhibitory activity. Thus, compound $\mathbf{2}$ could exert the inhibitory mechanisms by the interference of the $\mathrm{ADP}$ and platelet purinergic receptors (P2Y1 or P2Y12) interaction (15). Although the reference compound in the present study, ibuprofen, does not exhibit the inhibitory mechanism through the purinergic receptor intervention directly, the secondary wave caused by ADP-induced thromboxane formation was inhibited by this drug (16). Moreover, direct ADP receptor antagonists, namely clopidogrel and prasugrel, are needed liver biotransformation to form active metabolites (17). Therefore, the reference compound in vitro platelet aggregation assay was not readily available. Thus, the $\mathrm{IC}_{50}$ value of the reference compound is markedly higher than a biotransformed ADP receptor antagonist.

The inhibitory activity of oligostilbenes on the thromboxane A2 signaling pathways was determined. The platelet cyclooxygenase-1 (pCOX-1) is one of the critical steps in platelet activation via the synthesis of potent physiological lipid mediator, TxA2, by using AA as a substrate $(18,19)$. The obtained results indicated that the inhibitory activities depended on the decreasing number of stilbene subunit and the structure of the oligostilbenes. The findings demonstrate that tetrameric stilbene was less potent than the trimeric and dimeric ones, significantly. The possible inhibitory mechanisms of $1,2,3$, and 4 could be the resulted of the di-oxygenation inhibition of pCOX1 or the interference with TxA2-thromboxane-prostanoid (TP) receptor interaction. The TxA2 is a potent lipid mediator that acts as a platelet aggregation agonist through the TP receptor stimulation (20). To differentiate the mechanism of inhibition of TP receptor interference from pCOX-1 inhibition, the stable synthetic TxA2 analog, U-46619, was utilized to investigate the inhibitory mechanism of $1,2,3$, and 4 . The results indicated that the tetrameric stilbene $\mathbf{1}$ was more potent than the trimeric derivative 2. It allowed us to presume that either number of subunit or structural type affected the inhibitory activities. It was also found that the structural differences between 3 and 4 affected inhibitory activities. These findings allowed us to conclude that those of oligostilbenes 1,2 , 3 , and 4 inhibited the cyclooxygenase-dependent platelet activation pathways through the enzymatic inhibition of pCOX-1. Only compound $\mathbf{1}$ had interferential effects either on pCOX-1 catalysis or TxA2-TP receptor binding.

The platelet activation through the platelet proteaseactivated receptors (pPARs) by thrombin was utilized to evaluate the inhibitory potential of the oligostilbenes (21). The findings revealed that tetrameric stilbene $\mathbf{1}$ was active in thrombin catalyzed platelet aggregation but was inactive in TRAP-6 induced platelet aggregation. The results allowed us to conclude that $\mathbf{1}$ inhibited the proteolytic activity of the thrombin without the interference of thrombin receptor-activating peptide- 6 and PARs interaction. Collagen, the predominant sub-endothelial matrix, activates platelet through the glycoprotein (GP) VI and integrin $\alpha 2 \beta 1$ (22). The inhibitory effects of oligostilbenes on platelet collagen-induced platelet aggregation were investigated. The results revealed that compounds 1-4 were inactive in the collagen-induced human platelet aggregation assay.

\section{Conclusion}

Our findings demonstrate the inhibitory activities of the oligostilbenes on the in vitro human platelet aggregation through target-specific assay. The therapeutic applications of these active oligostilbenes could be TxA2 (compounds 1-4) and platelet purinergic receptor (compound 2) antagonists. The potent enzyme inhibitors for pCOX-1 (compounds 1-4) and thrombin (compound 1) were also demonstrated the plausible option for atherosclerosis related diseases. Although the findings demonstrated the antiplatelet activities of the oligostilbenes from $G$. macrostachyum, the activities represented the receptor interaction and enzymatic inhibition levels. Intensive studies are needed to distinguish the exact mechanisms of inhibition of these oligostilbenes, such as enzyme kinetic study (pCOX and thrombin), receptor binding affinity and differentiation (P2Y1/P2Y12, TP, and PARs receptors), calcium-mediated signaling, and intracellular signaling pathway interferences (phospholipase C, protein kinase C, phosphoinositide-3 kinase, and mitogen-activated protein kinases) (23-26).

\section{Authors' contribution}

SS designed the experiment, conducted the project, and wrote the paper. NS took part in the experiment and contributed the support on the basic and clinical pharmacology of antiplatelet drugs. All authors read and confirmed publication of the paper.

\section{Conflict of interests}

The authors declare no conflict of interest.

\section{Ethical considerations}

The authors affirm that all research protocol on human subject was approved by the Human Ethics Committee of the University of Phayao (Ethical code No. 2/018 and 0489/58). 


\section{Funding/Support}

The authors are grateful to the University of Phayao for financial support (AHS-RD-59012). The project was also partly supported by the Fundamental Fund for the Unit of Excellence Initiative (FF64-UoE007).

\section{Acknowledgments}

The authors are thankful to Prof. Dr. Santi Tippyang, Department of Chemistry, Faculty of Sciences, Chulalongkorn University for providing authentic oligostilbenes throughout the study. We are also grateful for our undergraduate students, Sinchai Chaikham, Jakkrit Buatana, Mattawan Meethangdee, Jarinya Luangapirom, Napatjaree Sopin, and Kitipong Jantabut, from the program in Medical Technology, School of Allied Health Sciences, University of Phayao in parts of experimental assistances.

\section{References}

1. Holinstat M. Normal platelet function. Cancer Metastasis Rev. 2017;36(2):195-8. doi: 10.1007/s10555-017-9677-x.

2. Koupenova M, Kehrel BE, Corkrey HA, Freedman JE. Thrombosis and platelets: an update. Eur Heart J. 2017;38(11):785-91. doi: 10.1093/eurheartj/ehw550.

3. Shim EJ, Ryu CW, Park S, Lee HN, Shin HS, Kim SB. Relationship between adverse events and antiplatelet drug resistance in neurovascular intervention: a meta-analysis. J Neurointerv Surg. 2018;10(10):942-8. doi: 10.1136/ neurintsurg-2017-013632.

4. Srivastava KC, Bordia A, Verma SK. Curcumin, a major component of food spice turmeric (Curcuma longa) inhibits aggregation and alters eicosanoid metabolism in human blood platelets. Prostaglandins Leukot Essent Fatty Acids. 1995;52(4):223-7. doi: 10.1016/0952-3278(95)90040-3.

5. Lee CL, Yen MH, Chang FR, Wu CC, Wu YC. Antiplatelet aggregation effects of phenanthrenes from Calanthe arisanensis. Nat Prod Commun. 2014;9(1):83-4. doi: 10.1177/1934578x1400900124.

6. Chen JJ, Chang YL, Teng CM, Chen IS. Anti-platelet aggregation alkaloids and lignans from Hernandia nymphaeifolia. Planta Med. 2000;66(3):251-6. doi: 10.1055/ s-2000-8562.

7. Saisin S, Tip-pyang S, Phuwapraisirisan P. A new antioxidant flavonoid from the lianas of Gnetum macrostachyum. Nat Prod Res. 2009;23(16):1472-7. doi: $10.1080 / 14786410802280943$.

8. Seo C, Lym SH, Jeong W, Lee JE, Lee JA, Ahn EK, et al. Flavonoids, stilbenoids, and phenolic derivatives from the stems of Gnetum macrostachyum (Gnetaceae). Biochem Syst Ecol. 2020;90:104033. doi: 10.1016/j.bse.2020.104033.

9. Kloypan C, Jeenapongsa R, Sri-in P, Chanta S, Dokpuang D, Tip-pyang S, et al. Stilbenoids from Gnetum macrostachyum attenuate human platelet aggregation and adhesion. Phytother Res. 2012;26(10):1564-8. doi: 10.1002/ptr.4605.

10. Sri-in P, Sichaem J, Siripong P, Tip-pyang S. Macrostachyols A-D, new oligostilbenoids from the roots of Gnetum macrostachyum. Fitoterapia. 2011;82(3):460-5. doi: 10.1016/j.fitote.2010.12.008.

11. Born GV. Aggregation of blood platelets by adenosine diphosphate and its reversal. Nature. 1962;194:927-9. doi: 10.1038/194927b0.

12. Lordkipanidzé M, Lowe GC, Kirkby NS, Chan MV, Lundberg $\mathrm{MH}$, Morgan NV, et al. Characterization of multiple platelet activation pathways in patients with bleeding as a high-throughput screening option: use of 96well Optimul assay. Blood. 2014;123(8):e11-22. doi: 10.1182/ blood-2013-08-520387.

13. Chaikham S, Buatana J, Meethangdee M, Luang-apirom J, Sopin N, Jantabut K, et al. Alkaloids from Nauclea orientalis inhibited in vitro ADP and thrombin induced human platelet aggregation. Sci Tech Asia. 2017;22(2):61-7. doi: 10.14456/tijsat.2017.17.

14. Tsai YW, Wen YW, Huang WF, Chen PF, Kuo KN, Hsiao FY. Cardiovascular and gastrointestinal events of three antiplatelet therapies: clopidogrel, clopidogrel plus protonpump inhibitors, and aspirin plus proton-pump inhibitors in patients with previous gastrointestinal bleeding. J Gastroenterol. 2011;46(1):39-45. doi: 10.1007/s00535-0100299-0.

15. Kunapuli SP, Dorsam RT, Kim S, Quinton TM. Platelet purinergic receptors. Curr Opin Pharmacol. 2003;3(2):17580. doi: 10.1016/s1471-4892(03)00007-9.

16. Khan N, Farooq AD, Sadek B. Investigation of cyclooxygenase and signaling pathways involved in human platelet aggregation mediated by synergistic interaction of various agonists. Drug Des Devel Ther. 2015;9:3497-506. doi: $10.2147 /$ dddt.s84335.

17. Holmes DR Jr, Dehmer GJ, Kaul S, Leifer D, O'Gara PT, Stein CM. ACCF/AHA clopidogrel clinical alert: approaches to the FDA "boxed warning": a report of the American College of Cardiology Foundation Task Force on clinical expert consensus documents and the American Heart Association endorsed by the Society for Cardiovascular Angiography and Interventions and the Society of Thoracic Surgeons. J Am Coll Cardiol. 2010;56(4):321-41. doi: 10.1016/j. jacc.2010.05.013.

18. Vane JR, Bakhle YS, Botting RM. Cyclooxygenases 1 and 2. Annu Rev Pharmacol Toxicol. 1998;38:97-120. doi: 10.1146/ annurev.pharmtox.38.1.97

19. Patrono C. Biosynthesis and pharmacological modulation of thromboxane in humans. Circulation. 1990;81(1 Suppl):I12-5.

20. Patrono C, Ciabattoni G, Davi G. Thromboxane biosynthesis in cardiovascular diseases. Stroke. 1990;21(12 Suppl):IV130-3.

21. Coughlin SR. Thrombin signalling and proteaseactivated receptors. Nature. 2000;407(6801):258-64. doi: $10.1038 / 35025229$.

22. Clemetson KJ, Clemetson JM. Platelet collagen receptors. Thromb Haemost. 2001;86(1):189-97. doi: 10.1055/s-00371616217.

23. Sangkuhl K, Shuldiner AR, Klein TE, Altman RB. Platelet aggregation pathway. Pharmacogenet Genomics. 2011;21(8):516-21. doi: 10.1097/FPC.0b013e3283406323.

24. Estevez B, Du X. New concepts and mechanisms of platelet activation signaling. Physiology (Bethesda). 2017;32(2):16277. doi: 10.1152/physiol.00020.2016.

25. Hechler B, Gachet C. P2 receptors and platelet function. Purinergic Signal. 2011;7(3):293-303. doi: 10.1007/s11302011-9247-6.

26. Rink TJ, Sage SO. Calcium signaling in human platelets. Annu Rev Physiol. 1990;52:431-49. doi: 10.1146/annurev. ph.52.030190.002243. 